\title{
СОДЕРЖАНИЕ ТЯЖЕЛЫХ МЕТАЛЛОВ В ПОЧВАХ СЕЛИТЕБНЫХ ТЕРРИТОРИЙ РЕСПУБЛИКИ КРЫМ
}

\section{Евстафьева Елена Владимировна',}

e.evstafeva@mail.ru

\section{Богданова Анна Михайловна',} annuta2607@yandex.ru

\author{
Минкина Татьяна Михайловна², \\ tminkina@mail.ru
}

Сушкова Светлана Николаевна²,
svetlana.sushkova.sfedu@gmail.com

\author{
Барановская Наталья Владимировна ${ }^{3}$ \\ nata@tpu.ru
}

\section{Манджиева Саглара Сергеевна ${ }^{2}$ msaglara@mail.ru}

\author{
Антоненко Елена Михайловна², \\ emantonenko@sfedu.ru

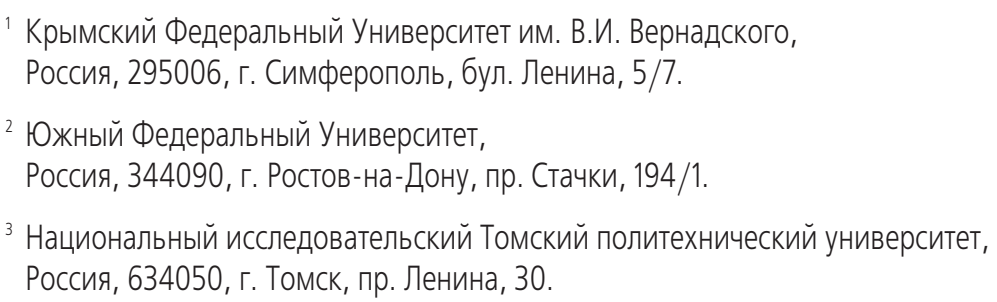

Актуальность работы обусловлена необходимостью мониторинга содержания тяжелых металлов в компонентах экосистем и биосубстратах человека как начального этапа исследований по оценке их воздействия на экосистемы и здоровье населения с целью установления региональных экологических нормативов содержания с учетом природной и техногенной специфики региона.

Цель работы: определить и оценить валовое содержание $\mathrm{Pb}, \mathrm{Zn}, \mathrm{Sr}, \mathrm{Cu}, \mathrm{Ni}, \mathrm{Co}, \mathrm{Cr}, \mathrm{As}, \mathrm{V}$ в почвах 30 площадок мониторинга селитебных территорий городов и поселков центрального, южного, восточного, северо-западного, западного и северного регионов Крымского полуострова.

Методы. Валовое содержание Pb, Zn, Sr, Cu, Ni, Co, Cr, As, V в почвах определяли на рентгенфлюоресцентном спектрометре «Спектроскан Макс-GV».

Результаты. Чаще всего превышения предельно допустимых концентраций (ПДК) и (или) кларков на территории полуострова имели место для $\mathrm{Cr}$, Co, Pb, в меньшей степени As n Zn. Максимальные величины превышений отдельных металлов достигали следующих значений: As (6,6 ПДК), Рb (2,1 ПДК), V (1,1 ПДК), Zn (1,7 ОДК), Ni (1,1 ОДК), Сo (2,8 кларка почв населенных пунктов), Си (2,6 кларка почв населенных пунктов), Cr (1,7 кларка почв населенных пунктов), Sr (1,7 кларка почв населенных пунктов). Сравнительный анализ распределения содержания тяжелых металлов с величинами кларков, природной и техногеннойхарактеристикой регионов позволяет предположить, что выявлено содержание тяжелых металлов в значительной степени имеет антропогенное происхождение. Для уточнения геохимической характеристики почв и ее происхождения необходимы дальнейшие исследования, в том числе заповедных территорий Крыма.

\section{Ключевые слова:}

Почвы, тяжелые металлы, экологический мониторинг, селитебные территории, Крымский полуостров.

\section{Введение}

В настоящее время с целью изучения антропогенного воздействия на экосистемы и здоровье населения в Республике Крым ведутся комплексные медико-экологические исследования, главной задачей которых является интеграция медицинских и экологических данных, моделирование и прогнозирование на их основе состояния здоровья насе- ления в связи с возможным ухудшением экологической ситуации в результате той или иной хозяйственной деятельности на конкретных территориях $[1,2]$. Поскольку в качестве базовой экологической связи между компонентами экосистем, включая человека, рассматриваются биогеохимические трофические цепи [3], важной составляющей данных исследований является геоэкологиче- 
ская оценка различных районов Республики Крым с последующим мониторингом здоровья населения на этих территориях. Увеличение антропогенной нагрузки на все компоненты биосферы, особенно в городской среде, приводит к изменению состава (преимущественно микроэлементного) и свойств почв [4-7].

Тяжелые металлы (ТM) являются одной из наиболее опасных категорий загрязняющих веществ. Попадая в растения из почвы и воздуха, они способны аккумулироваться в растительных тканях в большом количестве и по трофической цепочке переходить в организм животных, а затем и человека. Вследствие деятельности промышленных предприятий происходит активное накопление ТМ в растениях, что может отчетливо проявиться во времени [8, 9].

В свою очередь почвы являются первым звеном в биогеохимической пищевой цепи и начальным этапом миграции тяжелых металлов в системе «почва - растение - животное - продукт питания человек» [10-13].

Проблема снижения влияния ТМ на токсичность почв обусловлена отсутствием механизмов природного самоочищения от этой группы химических элементов, так как в ходе миграции они меняют только уровень содержания или формы нахождения.

С 2008 г. для оценки экологической ситуации на территории Крымского полуострова кроме традиционных отечественных нормативов содержания ТМ в почвах используют экосистемные экологические нормативы - критические нагрузки (КН), рекомендованные экспертами Конвенции Long Range Transboundary Air Pollution, которые рассчитаны и картированы для территории Крымского полуострова в масштабе $5 \times 5$ км [1]. Также выполняются полевые исследования по определению фактических выпадений ТМ с осадками на почвы и превышений этих экосистемных показателей в разных географических регионах полуострова. Учитывая, что природные условия и почвы Республики Крым характеризуются значительным разнообразием, а КН и их превышения рассчитывались на достаточно крупную площадь (ячейки сетки), для более точных оценок загрязнения почв ТМ остается актуальной необходимость дальнейшей детализации исследований геохимической характеристики почв и сравнения результатов, полученных с помощью отечественных и европейских подходов.

В связи с этим цель работы состояла в определении валового содержания ТМ в поверхностном слое почв селитебных территорий городов и сельской местности Крымского полуострова.

\section{Материалы и методики исследования}

Поскольку конечной целью осуществляемых исследований, фрагмент которых представлен в данной статье, является оценка поступления ТМ в организм человека по всем возможным путям, и, прежде всего, по биогеохимическим трофическим цепям, образцы почв отбирали преимущественно на селитебных территориях сельской местности, а также для сравнения в парковых и селитебных зонах городов, расположенных в непосредственной близости к месту проживания контингента жителей, в отношении которых в дальнейшем планировалось биомониторинговое исследование на предмет содержания ТМ в их организме.

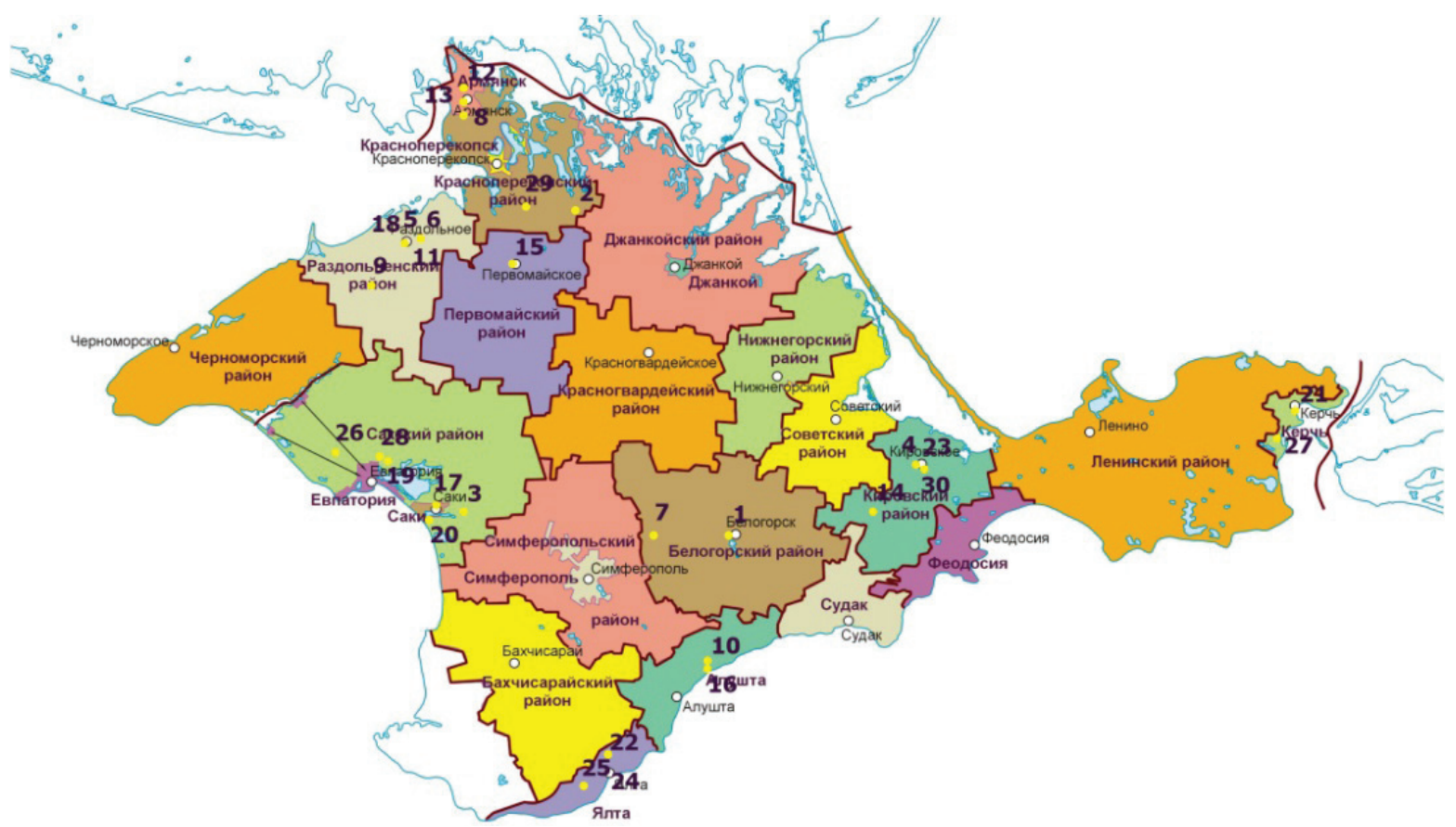

Рисунок. Расположение площадок мониторинга в административных районах Республики Крым

Figure. Location of monitoring plots in the administrative regions of Crimea Republic 
В октябре 2016 г. были заложены площадки мониторинга (рисунок) на территориях следующих 11 из 25 административно-территориальных единиц и соответствующих муниципальных образований Республики Крым:

1) районы (муниципальные районы): Белогорский, Кировский, Красноперекопский, Первомайский, Раздольненский, Сакский;

2) города республиканского значения (городские округа): Алушта, Армянск, Керчь, Саки, Ялта. Указанные административно-территориальные единицы относятся к северному, западному, северо-западному, центральному, восточному и южному регионам Крымского полуострова (табл. 1). Для северных территорий характерен степной ландшафт и развитая сельскохозяйственная и промышленная деятельность. На западных и северо-западных территориях помимо этого находятся бальнеогрязевые курорты. Белогорский район, расположенный в предгорьях центральной части полуострова, характеризуется преобладанием сел и поселков над городами и развитой сельскохозяйственной деятельностью. Территорию восточного региона занимает Присивашская степь и предгорья, где находятся камнедобывающие карьеры, а также развито сельскохозяйственное производство. Юго-западная часть восточного региона преимущественно равнинная, степная, встречается много грязевых вулканов, имеются карьеры по добыче руд, ракушечника, известняка, выращиваются сельскохозяйственные культуры. Южный регион расположен в предгорьях, здесь развито виноградарство, активна деятельность санаторно-курортных учреждений.

Таким образом, мониторинговые площадки не только располагались в разных географических регионах Крымского полуострова, но и представляли собой селитебные территории с разной в качественном и количественном отношении антропогенной нагрузкой.

Пробы почв отбирали цилиндрическим пробоотборником из нержавеющей стали с глубины $0-15$ см методом «квадратного конверта» со стороной 1-2 м. Каждая проба почвы была составлена из девяти точечных проб. Пять проб отбирали по углам и в центре квадратного конверта, а еще четы-

Таблица 1. Расположение площадок мониторинга в географических районах Республики Крым

Table 1. Location of monitoring plots in the geographical regions of Crimea Republic

\begin{tabular}{|c|c|c|c|}
\hline $\begin{array}{l}\text { Peгион } \\
\text { Region }\end{array}$ & $\begin{array}{l}\text { Paйон } \\
\text { Area }\end{array}$ & \begin{tabular}{|c|} 
№ площадки \\
Plot no.
\end{tabular} & $\begin{array}{l}\text { Населенный пункт } \\
\text { Locality }\end{array}$ \\
\hline \multirow{5}{*}{$\begin{array}{l}\text { Северный } \\
\text { Northern }\end{array}$} & \multirow{2}{*}{$\begin{array}{l}\text { Красноперекопский } \\
\text { Krasnoperekopsky }\end{array}$} & 2 & с. Магазинка/Magazinka \\
\hline & & 29 & с. Новопавловка/Novopavlovka \\
\hline & \multirow{3}{*}{$\begin{array}{l}\text { Aрмянск } \\
\text { Armyansk }\end{array}$} & 8 & г. Apмянск/Armyansk \\
\hline & & 12 & с. Перекоп/Perekop \\
\hline & & 13 & с. Суворово/Suvorovo \\
\hline \multirow{6}{*}{$\begin{array}{c}\text { Северо-Западный } \\
\text { Northwestern }\end{array}$} & \multirow{5}{*}{$\begin{array}{l}\text { Раздольненский } \\
\text { Razdolnensky }\end{array}$} & 5 & пгт. Раздольное, 1 км от шоссе/Razdolnoe, 1 km from the road \\
\hline & & 6 & с. Ботаническое/Botanicheskoe \\
\hline & & 9 & с. Орловка/Orlovka \\
\hline & & 11 & пгт. Раздольное, парковая зона/Razdolnoe, park zone \\
\hline & & 18 & ппт. Раздольное, 800 м от шоссе/Razdolnoe, 1 km from the road \\
\hline & $\begin{array}{l}\text { Первомайский } \\
\text { Pervomaysky }\end{array}$ & 15 & пгт. Первомайское/Pervomayskoe \\
\hline \multirow{6}{*}{$\begin{array}{l}\text { Западный } \\
\text { Western }\end{array}$} & \multirow{5}{*}{$\begin{array}{l}\text { Сакский } \\
\text { Saksky }\end{array}$} & 3 & с. Червоное/Chervonoe \\
\hline & & 19 & с. Каменоломня, Зкм от шоссе/Kamenolomnya, $3 \mathrm{~km}$ from the road \\
\hline & & 20 & с. Новофедоровка/Novofedorovka \\
\hline & & 26 & с. Ромашкино/Romashkino \\
\hline & & 28 & с. Каменоломня, 2 км от шоссе/Kamenolomnya, 2 km from the road \\
\hline & Саки/Saki & 17 & г. Саки/Saki \\
\hline \multirow{2}{*}{$\begin{array}{l}\text { Центральный } \\
\text { Central }\end{array}$} & \multirow{2}{*}{$\begin{array}{l}\text { Белогорский } \\
\text { Belogorsky }\end{array}$} & 1 & г. Белогорск/Belogorsk \\
\hline & & 7 & ппт. Зуя/Zuya \\
\hline \multirow{6}{*}{$\begin{array}{l}\text { Восточный } \\
\text { Eastern }\end{array}$} & \multirow{4}{*}{$\begin{array}{l}\text { Кировский } \\
\text { Kirovsky }\end{array}$} & 4 & с. Яркое поле, 1,7 км от шоссе/Yarkoe pole, 1,7 km from the road \\
\hline & & 14 & с. Приветное/Privetnoe \\
\hline & & 23 & с. Яркое поле, 1,5 км от шоссе/Yarkoe pole, 1,5 km from the road \\
\hline & & 30 & с. Яркое поле, 350 м от шоссе/Yarkoe pole, $350 \mathrm{~m}$ from the road \\
\hline & \multirow[b]{2}{*}{$\begin{array}{l}\text { Kepub } \\
\text { Kerch }\end{array}$} & 21 & г. Керчь, 500 м от Морского торгового порта/Kerch, 500 m from the seaport \\
\hline & & 27 & \begin{tabular}{|l} 
г. Керчь, р-н бухты Камыш-Бурунской, 500 м от теплоэлектростанции \\
Kerch, Kamysh-Burunskaya cove, 500 m from the electro station
\end{tabular} \\
\hline \multirow{5}{*}{$\begin{array}{l}\text { Южный } \\
\text { Southern }\end{array}$} & \multirow{2}{*}{$\begin{array}{l}\text { Алушта } \\
\text { Alushta }\end{array}$} & 10 & $\begin{array}{l}\text { г. Алушта, } 100 \text { м от автозаправочной станции } \\
\text { Alushta, } 100 \mathrm{~m} \text { from the petrol station }\end{array}$ \\
\hline & & 16 & $\begin{array}{l}\text { г. Алушта, } 400 \text { м от транспортной развязки } \\
\text { Alushta, } 400 \mathrm{~m} \text { from the road junction }\end{array}$ \\
\hline & \multirow{3}{*}{$\begin{array}{l}\text { Ялта } \\
\text { Yalta }\end{array}$} & 22 & г. Ялта, 450 м от шоссе, парковая зона/Yalta, $450 \mathrm{~m}$ from the road, park zone \\
\hline & & 24 & г. Ялта, 400 м от шоссе/Yalta, $400 \mathrm{~m}$ from the road \\
\hline & & 25 & пгт. Кореиз/Koreiz \\
\hline
\end{tabular}


ре - внутри него. Всего было отобрано 30 проб почв. Их отбор, хранение и транспортировка осуществлялись в соответствии с ГОСТ 17.4.4.02-84 [14], МУ 2.1.7.730-99 [15]. Предварительная подготовка почвы для проведения анализа проводилась в соответствии с ГОСТ 29269-91 [16]. Проанализировано 90 почвенных образцов (3 повторности измерений).

В почвенных пробах определяли валовое содержание ТМ первого класса опасности (As, Pb, Zn), второго класса опасности $(\mathrm{Cu}, \mathrm{Ni}, \mathrm{Co}, \mathrm{Cr})$ и третьего класса опасности $(\mathrm{V}, \mathrm{Sr})$ на рентгенфлуоресцентном спектрометре «Спектроскан Макс-GV» в лаборатории кафедры почвоведения и оценки земельных ресурсов Академии биологии и биотехнологии им. Д.И. Ивановского Южного Федерального Университета.

Содержание ТМ сопоставляли с предельно допустимыми концентрациями (ПДК) и ориентировочно допустимыми концентрациями (ОДК) химических веществ в почве $[17,18]$. При отсутствии нормативов содержание загрязняющих веществ сравнивали с их средними значениями (кларками) в почвах населенных пунктов по данным В.А. Алексеенко [19].

Кроме рассмотренных нормативов, для оценки загрязнения почв ТМ в настоящее время используют показатели, полученные на основе соотнесения фактических концентраций с кларками почв населенных пунктов: коэффициент техногенной концентрации элемента и суммарный коэффициент техногенного загрязнения [20].

Коэффициент техногенной концентрации элемента $\left(K_{c}\right)$ рассчитывается следующим образом:

$$
K_{c}=C_{i} / K,
$$

где $C_{i}$ - содержание элемента в исследуемой почве; $K$ - кларк почв населенных пунктов.

При загрязнении почвы двумя и более элементами производится расчет суммарного показателя загрязнения $\left(Z_{c}\right)$ :

$$
Z_{c}=\sum_{i=1}^{n} K_{c}-(n-i)
$$

где $K_{c}-$ коэффициенты техногенной концентрации, превышающие $1 ; n$ - число элементов с $K_{c}>1$.

При этом уровень загрязнения считается низким, если $Z_{c}$ находится в пределах 0-16; средним (умеренно опасным), если $Z_{c}=16-32$; высоким (опасным), если $Z_{c}=32-128$; очень высоким (чрезвычайно опасным), если $Z_{c}>128$.

Данный показатель при использовании его для оценки воздействия техногенного объекта на окружающую среду является, на наш взгляд, более информативным, чем ПДК, так как отражает относительную динамику рассматриваемых показателей и, отчасти, учитывает их совместное воздействие.

Поскольку задача исследования заключалась, прежде всего, в получении качественной картины распределения TM в почвах селитебных территорий разных в географическом и техногенном отношении регионов полуострова, ее оценивали по среднему значению (Mean), стандартному отклонению (SD), а также минимальным ( $\min )$ и максимальным (max) значениям валового содержания.

\section{Результаты исследования и обсуждение}

Анализ данных по распределению элементов в почвах исследуемых территорий Крымского полуострова показал наличие превышений референтных значений по различным регионам для $\mathrm{Cr}, \mathrm{Co}$, $\mathrm{Pb}$, в то время как превышение содержания остальных элементов встречались только на некоторых площадках мониторинга. Исключение составил Zn, повышенное содержание которого наблюдали для двух из шести площадок мониторинга в г. Саки и населенных пунктах Сакского района, и V, превышение которого отмечено в обеих пробах почв Красноперекопского района. При этом максимальная степень превышений для разных металлов составила: As (6,6 ПДК), Pb (2,1 ПДК), V (1,1 ПДК), Zn (1,7 ОДК), $\mathrm{Ni}(1,1$ ОДК), Со (2,8 кларка почв населенных пунктов), $\mathrm{Cu}$ (2,6 кларка почв населенных пунктов), $\mathrm{Cr}$ (1,7 кларка почв населенных пунктов), $\mathrm{Sr}$ (1,7 кларка почв населенных пунктов) (табл. 2).

Более детальный анализ полученных данных позволяет констатировать следующее. В верхних горизонтах почв селитебных зон Крымского полуострова V содержится в количестве от 19,4 до 171,0 мг/кг при средней концентрации $92,0 \pm 41,5$ мг/кг. Почти в $97 \%$ случаев содержание данного элемента находилось в пределах ПДК. При этом разброс средних значений $\mathrm{V}$ по регионам составил от 64,0 мг/кг в Белогорском районе до 115,0 мг/кг в восточном регионе. Превышение 1,14 ПДК было обнаружено на площадке № 2 (с. Магазинка, Красноперекопский район). В 50 \% случаев содержание V превышало кларк почв населенных пунктов в 1,05-1,6 раз (г. Алушта, г. Саки, Сакский район, Керчь, пгт. Раздольное, г. Ялта, Кировский район, Красноперекопский район).

Содержание $\mathrm{Cr}$ на всех исследуемых участках превышало его кларк для почв населенных пунктов в 1,1-1,7 раз (г. Алушта, пгт. Раздольное, Сакский район, г. Ялта, Кировский район, Красноперекопский район) и составляло от 42,3 до 139,5 мг/кг при средней концентрации 77,5 23,6 мг/кг. Разброс средних значений этого элемента по регионам составил от 60,9 мг/кг в Белогорском районе до 86,9 мг/кг в почвах восточного региона.

Среднее содержание Со составило 18,2 $\pm 8,7$ мг/кг, при этом значения варьировали от 1,4 до 39,9 мг/кг. Валовое содержание Со превысило кларк элемента в 1,1-2,8 раз на исследуемых участках (г. Ялта, г. Алушта, г. Керчь, Кировский район, Сакский район, г. Саки, Раздольненский район, Красноперекопский район). Наиболее высоких значений содержание Сo (32,3 и 39,9 мг/кг), так же как для V и $\mathrm{Cr}$, достигало в верхнем слое почв площадок мониторинга № 2 (с. Магазинка) и № 29 (с. Новопавловка) северной части полуострова, что предположительно может быть связано с деятельностью 
Таблица 2. Валовое содержание тяжелых металлов в почвах площадок мониторинга селитебных зон Республики Крым, мг/Кг

Table 2. Total content of heavy metals in soils of monitoring plots in residential zones of Crimea Republic, $\mathrm{mg} / \mathrm{kg}$

\begin{tabular}{|c|c|c|c|c|c|c|c|c|c|c|}
\hline $\begin{array}{c}\text { Район } \\
\text { Area }\end{array}$ & 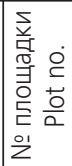 & V & $\mathrm{Cr}$ & Co & $\mathrm{Ni}$ & $\mathrm{Cu}$ & Zn & As & Sr & $\mathrm{Pb}$ \\
\hline \multicolumn{11}{|c|}{ Северный регион/Northern region } \\
\hline \multirow{2}{*}{$\begin{array}{l}\text { Kрасноперекоп- } \\
\text { ский } \\
\text { Krasnoperekopsky }\end{array}$} & 2 & 171 & 123 & 32 & 86 & 74 & 158 & - & 172 & 51 \\
\hline & 29 & 150 & 139 & 40 & 73 & 99 & 160 & - & 372 & 16 \\
\hline \multirow{3}{*}{$\begin{array}{l}\text { Aрмянск } \\
\text { Armyansk }\end{array}$} & 8 & 33 & 51 & 1 & 18 & 83 & 90 & - & 293 & - \\
\hline & 12 & 19 & 46 & - & - & 77 & 83 & - & 282 & - \\
\hline & 13 & 22 & 42 & - & - & 76 & 79 & - & 278 & 1 \\
\hline \multicolumn{11}{|c|}{ Северо-западный регион/Northwestern region } \\
\hline \multirow{5}{*}{$\begin{array}{l}\text { Раздольненский } \\
\text { Razdolnensky }\end{array}$} & 5 & 124 & 88 & 26 & 56 & 71 & 158 & - & 219 & 25 \\
\hline & 6 & 59 & 59 & 6 & 32 & 29 & 70 & 13 & 143 & 40 \\
\hline & 9 & 72 & 67 & 17 & 29 & 65 & 158 & - & 333 & 40 \\
\hline & 11 & 23 & 46 & - & - & 76 & 78 & - & 288 & - \\
\hline & 18 & 121 & 90 & 24 & 45 & 52 & 236 & - & 421 & 68 \\
\hline $\begin{array}{l}\text { Первомайский } \\
\text { Pervomaysky }\end{array}$ & 15 & 26 & 47 & - & - & 74 & 76 & - & 285 & - \\
\hline \multicolumn{11}{|c|}{ 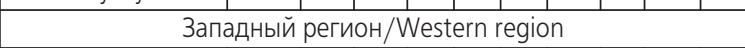 } \\
\hline \multirow{5}{*}{$\begin{array}{l}\text { Сакский } \\
\text { Saksky }\end{array}$} & 3 & 124 & \begin{tabular}{|l|}
97 \\
\end{tabular} & 25 & 61 & 52 & \begin{tabular}{|l|}
115 \\
\end{tabular} & \begin{tabular}{|l|}
11 \\
\end{tabular} & \begin{tabular}{|l|}
181 \\
\end{tabular} & 25 \\
\hline & 19 & 78 & 60 & 14 & 28 & 60 & 120 & \begin{tabular}{|l|}
- \\
\end{tabular} & 267 & 10 \\
\hline & 20 & 93 & 74 & 13 & 46 & 51 & 172 & - & 229 & 3 \\
\hline & 26 & 117 & 89 & 18 & 55 & 66 & 347 & - & 245 & 24 \\
\hline & 28 & 75 & 62 & 17 & 27 & 63 & 89 & - & 351 & - \\
\hline Саки/Saki & 17 & 111 & 83 & 23 & 56 & 52 & 373 & - & 230 & 35 \\
\hline \multicolumn{11}{|c|}{ Центральный регион/Central region } \\
\hline \multirow{2}{*}{\begin{tabular}{|l|} 
Белогорский \\
Belogorsky
\end{tabular}} & 1 & 40 & 43 & 6 & 15 & 68 & 86 & \begin{tabular}{|l|}
- \\
\end{tabular} & 774 & 8 \\
\hline & \begin{tabular}{|l|}
7 \\
\end{tabular} & 90 & \begin{tabular}{|l|}
79 \\
\end{tabular} & 14 & 48 & 41 & 177 & 12 & 175 & 33 \\
\hline \multicolumn{11}{|c|}{ Восточный регион/Eastern region } \\
\hline \multirow{4}{*}{$\begin{array}{l}\text { Кировский } \\
\text { Kirovsky }\end{array}$} & 4 & 127 & \begin{tabular}{|l|}
98 \\
\end{tabular} & 23 & 63 & 55 & 101 & 13 & 152 & 37 \\
\hline & 14 & 115 & 102 & 28 & 61 & 53 & 102 & - & 131 & 29 \\
\hline & 23 & 129 & 93 & 23 & 58 & 50 & 98 & - & 168 & 23 \\
\hline & 30 & 122 & 90 & 22 & 58 & 48 & 95 & - & 142 & 23 \\
\hline \multirow{2}{*}{$\begin{array}{l}\text { Kepчь } \\
\text { Kerch }\end{array}$} & 21 & 83 & 61 & 13 & 27 & 40 & 147 & - & 246 & 25 \\
\hline & 27 & 118 & 78 & 20 & 44 & 55 & 96 & - & 140 & 28 \\
\hline \multicolumn{11}{|c|}{ Южный регион/Southern region } \\
\hline \multirow{2}{*}{\begin{tabular}{|l|} 
Алушта \\
Alushta
\end{tabular}} & \begin{tabular}{|l|}
10 \\
\end{tabular} & 68 & 67 & 17 & 28 & 35 & 93 & - & 121 & 26 \\
\hline & 16 & 110 & 86 & 4 & 54 & 42 & 106 & - & 135 & 19 \\
\hline \multirow{3}{*}{$\begin{array}{l}\text { Ялта } \\
\text { Yalta }\end{array}$} & 22 & 141 & 99 & \begin{tabular}{|l|}
19 \\
\end{tabular} & 56 & 51 & 197 & - & 247 & 31 \\
\hline & 24 & 81 & 77 & 12 & 27 & 35 & 74 & - & 128 & 36 \\
\hline & 25 & 118 & \begin{tabular}{|l|}
89 \\
\end{tabular} & \begin{tabular}{|l|}
15 \\
\end{tabular} & 50 & \begin{tabular}{|l|}
54 \\
\end{tabular} & \begin{tabular}{|l|}
114 \\
\end{tabular} & - & \begin{tabular}{|l|}
137 \\
\end{tabular} & 33 \\
\hline \multicolumn{2}{|c|}{$\begin{array}{l}П Д К ~ \\
\text { Maximum permissible } \\
\text { concentration [17] }\end{array}$} & 150 & - & - & - & - & - & 2 & - & 32 \\
\hline \multicolumn{2}{|c|}{$\begin{array}{l}\text { ОДК } \\
\text { Approximate permissible } \\
\text { concentration [18] }\end{array}$} & - & - & - & 80 & 132 & 220 & 10 & - & 130 \\
\hline \multicolumn{2}{|c|}{$\begin{array}{l}\text { Кларк почв населенных } \\
\text { пунктов по данным } \\
\text { Aлексеенко Soil clarck in } \\
\text { settlements on Alekseen- } \\
\text { ko [19] }\end{array}$} & 105 & 80 & 14 & 33 & 39 & 158 & 16 & 458 & 55 \\
\hline
\end{tabular}

Примечание: жирным шрифтом выделены величины, превышающие референтные значения.

Note: bold indicates above average reference values. промышленных предприятий г. Армянск и Красноперекопск. В то же время на площадках, расположенных на территории с. Суворово, с. Перекоп городского округа Армянск, пгт. Первомайское и пгт. Раздольное, концентрация этого элемента была ниже предела обнаружения. Разброс средних значений этого элемента по регионам составил от 9,9 мг/кг в Белогорском районе до 24,5 мг/кг в северном регионе.

Содержание Ni в почвах исследуемых районов не превышало ОДК, за исключением площадки мониторинга № 2, и варьировало от 14,0 до 86,4 мг/кг при среднем содержании $46,2 \pm 17,7$ мг/кг. В то же время содержание этого элемента на исследуемых участках в 57 \% случаев превышало кларк почв населенных пунктов в 1,3-2,6 раз. Распределение $\mathrm{Ni}$ в почвах исследуемых населенных пунктов по возрастанию было следующим: г. Керчь, пгт. Зуя, г. Алушта, г. Ялта $<$ Раздольненский район $<$ Кировский район, Сакский район $<$ Красноперекопский район. Концентрация Ni была ниже предела обнаружения на тех же площадках, что и для Со. Разброс средних значений $\mathrm{Ni}$ по регионам составил от 31,4 мг/кг в Белогорском районе до 59,4 мг/кг в почвах северного региона.

Содержание $\mathrm{Cu}$ и $\mathrm{Zn}$ в верхнем слое почв площадок мониторинга варьировало в широких пределах: от 28,7 до 99,3 мг/кг и от 70,4 до 372,9 мг/кг соответственно. Но при этом содержание $\mathrm{Cu}$ не превышало ОДК и составило в среднем $58,2 \pm 16,0$ мг/кг, однако превысило кларк почв населенных пунктов в 90 \% случаев в 1,1-2,6 раз. Его распределение в исследованных районах по возрастающей было следующим: пгт. Зуя, г. Алушта < г. Ялта, г. Керчь, Кировский район < Сакский район, Раздольненский район, г. Белогорск < пгт. Первомайское, с. Магазинка, г. Армянск. Содержание Zn не превышало ОДК за исключением трех площадок мониторинга (1,07-1,7 ОДК на площадках № 17, 18, 26 северо-западной и западной части полуострова), и составило в среднем $135,0 \pm 73,9$ мг/кг. Однако на семи площадках мониторинга содержание этого элемента превысило в 1,1-2,4 раз кларк почв населенных пунктов, при этом наблюдался следующий ряд по накоплению $\mathrm{Zn}$ в почвах этих площадок: с. Новопавловка < c. Новофедоровка < пгт. Зуя < г. Ялта $<$ пгт. Раздольное < с. Ромашкино $<$ г. Саки. Разброс средних значений элементов по регионам составил: для $\mathrm{Cu}$ - от 43,4 мг/кг в южном регионе до 81,8 мг/кг в северной части полуострова, Zn - от 106,6 мг/кг в восточном регионе до 202,5 мг/кг в западном регионе.

Концентрации As были выше порога определения лишь на четырех площадках мониторинга (с. Червоное, с. Яркое поле, с. Ботаническое, пгт. Зуя), при этом все они превышали ПДК данного элемента в $5,5-6,6$ раз, ОДК - в $1,1-1,3$ раз, но не превышали кларк почв населенных пунктов и колебались в узких пределах от 11,1 до 13,2 мг/кг. На остальных площадках содержание As было ниже предела обнаружения. 
Среднее содержание $\mathrm{Sr}$ составило $242,9 \pm 128,9$ мг/кг, при этом значения варьировали от 121,2 до 773,6 мг/кг и превышали кларк почв населенных пунктов в 1,7 раз на площадке № 1 (г. Белогорск). Разброс средних значений этого элемента по регионам составил от 153,8 мг/кг в южном регионе до 474,2 мг/кг в Белогорском районе.

Содержание $\mathrm{Pb}$ в верхнем слое селитебных почв изменялось в широких пределах: от 1,1 до 68,1 мг/кг, и составило в среднем $27,6 \pm 14,6$ мг/кг, при этом на 30 \% площадок мониторинга его содержание превысило ПДК в 1,1-2,1 раз (пгт. Кореиз, пгт. Зуя, г. Саки, г. Ялта, с. Яркое поле, с. Магазинка, Раздольненский район). Сравнение содержания этого элемента с кларком почв населенных пунктов обнаружило его превышение в 1,3 раза в с. Магазинка, расположенном в северной части полуострова. При этом в почвах пяти мониторинговых площадок содержание $\mathrm{Pb}$ было ниже предела обнаружения (с. Перекоп, г. Армянск, пгт. Первомайское, пгт. Раздольное, с. Каменоломня), включая площадки, в почвах которых не были выявлены такие элементы, как Со и Ni. Paзброс средних значений этого элемента по регионам составил от 19,5 мг/кг в западной части полуострова до 43,3 мг/кг в северо-западном регионе.

Таким образом, нами были получены данные для построения элементных рядов накопления TM. Так, в поверхностном слое почв северного региона (населенные пункты Красноперекопского района, г. Армянск и округа Армянск) полученные данные позволили построить следующий элементный ряд накопления ТМ по возрастанию их концентраций: $\mathrm{Co}<\mathrm{Pb}<\mathrm{Ni}<\mathrm{Cu}<\mathrm{Cr}<\mathrm{V}<\mathrm{Zn}<\mathrm{Sr}$. Coдержание всех элементов превышает ПДК, ОДК либо кларк почв населенных пунктов. Отмечено превышение кларков почв населенных пунктов для всех TM. Содержание V, превышающее ПДК в 1,1 раз, $\mathrm{Pb}$ - в 1,6 раз и $\mathrm{Ni}$, превышающего ОДК в 1,1 раз, установлено в почвах населенных пунктов Красноперекопского района, что, вероятнее всего, обусловлено производством титановых сплавов и сталей различных сортаментов 000 «Титановые Инвестиции - Крымский Титан». Также повышение содержания ТМ может быть связано с деятельностью промышленных предприятий, в том числе химической отрасли, расположенных в северной части полуострова. Так, в 2014 г. 63,2 и 33,0 \% отходов Крыма приходилось на промышленные предприятия г. Красноперекопск и Армянск, которые являлись самыми загрязненными территориями по отходам на $1 \mathrm{kм}^{2}[21]$.

Элементные ряды накопления по возрастанию концентраций в поверхностном слое почв селитебных зон северо-западного региона (населенные пункты Раздольненского и Первомайского районов) были следующие: $\mathrm{As}<\mathrm{Co}<\mathrm{Ni}<\mathrm{Pb}<\mathrm{Cu}<\mathrm{V}<\mathrm{Cr}<\mathrm{Zn}<\mathrm{Sr}$ и $\mathrm{V}<\mathrm{Cr}<\mathrm{Cu}<\mathrm{Zn}<\mathrm{Sr}$. Отмечено превышение кларка почв населенных пунктов для всех элементов, кроме $\mathrm{Sr}$, и превышение ОДК $\mathrm{Zn}$ в 1,1 раз и ПДК
$\mathrm{Pb}$ в 2,1 раз в пгт. Раздольное. В то же время из трех исследованных площадок на участке, расположенном в парковой зоне, и на мониторинговой площадке в Первомайском районе содержание $\mathrm{Co}, \mathrm{Ni}, \mathrm{As}, \mathrm{Pb}$ было ниже предела обнаружения, превышение кларка почв населенных пунктов было установлено только для $\mathrm{Cu}$. В с. Ботаническое и с. Орловка отметили превышение кларка почв населенных пунктов для $\mathrm{Co}$ и $\mathrm{Cu}, 1,3$ ПДК $\mathrm{Pb}$, а также 6,6 ПДК As на территории с. Ботаническое (площадка № 6). Так как As был обнаружен лишь на четырех площадках из 30 , его источником, скорее всего, являются отходы либо атмосферный перенос с расположенных рядом сельскохозяйственных угодий, где использовались пестициды. Более высокое содержание $\mathrm{Zn}, \mathrm{Ni}, \mathrm{Co}$ и $\mathrm{Cu}$ может быть связано с тем, что на территории северо-западной части полуострова преобладающими типами почв являются в том числе черноземы средне- и тяжелосуглинистые на красно-бурых глинах [22].

Превышение содержания $\mathrm{Pb}$ в северо-западном регионе на площадках № $6,9,18$ может быть связано с выбросами автотранспорта [23], так как участки были расположены в зоне не более 1 км от дорожных трасс. Другой причиной может быть перенос $\mathrm{Pb}$ с атмосферным воздухом и осадками, что подтверждается ранее проведенными исследованиями $[1,24]$, в соответствии с которыми были отмечены превышения на 80,7 \% допустимой критической нагрузки свинца его фактическим выпадением на площадке, территориально близкой к заповеднику «Лебяжьи острова» .

Для почв сел Сакского района (Червоное, Каменоломня, Новофедоровка, Ромашкино) и для почв г. Саки западного региона были установлены следующие элементные ряды накопления по возрастанию их содержания: $\mathrm{As}<\mathrm{Pb}<\mathrm{Co}<\mathrm{Ni}<\mathrm{Cu}<\mathrm{Cr}<\mathrm{V}<\mathrm{Zn}<\mathrm{Sr}$ в поселках и $\mathrm{Co}<\mathrm{Pb}<\mathrm{Cu}<\mathrm{Ni}<\mathrm{Cr}<\mathrm{V}<\mathrm{Sr}<\mathrm{Zn}$. В г. Саки концентрация $\mathrm{Pb}$ в почвах превысила ПДК на $12 \%$. В почвах мониторинговых площадок г. Саки, c. Ромашкино и с. Червоное содержание V, Cr, Co, $\mathrm{Ni}, \mathrm{Cu}$ превышало либо было близко к кларкам почв населенных пунктов. Также на этих участках выявлено превышение 1,6-1,7 ОДК Zn. В почве участка в с. Новофедоровка только содержание $\mathrm{Cu}$ и Zn было выше значений кларка почв населенных пунктов. В поверхностном слое почв площадок мониторинга в с. Каменоломня были обнаружены превышения кларка почв населенных пунктов для $\mathrm{Co}$ и $\mathrm{Cu}$.

Для территорий центрального региона были установлены следующие элементные ряды накопления по возрастанию их концентраций в поверхностном слое селитебных почв г. Белогорск и пгт. Зуя: $\mathrm{Co}<\mathrm{Pb}<\mathrm{Ni}<\mathrm{V}<\mathrm{Cr}<\mathrm{Cu}<\mathrm{Zn}<\mathrm{Sr}$ и $\mathrm{As}<\mathrm{Co}<\mathrm{Pb}<\mathrm{Cu}<\mathrm{Ni}<\mathrm{Cr}<\mathrm{V}<\mathrm{Sr}<\mathrm{Zn}$. В г. Белогорск выявлено превышение кларка $\mathrm{Cu}$ для почв населенных пунктов, самая высокая концентрация Sr. В пгт. Зуя содержание $\mathrm{Ni}, \mathrm{Zn}$ превышало кларки этих элементов в почвах населенных пунктов, кон- 
центрация As превышала ПДК в 6,2 раз. В почве мониторинговой площадки пгт. Зуя было обнаружено превышение ПДК $\mathrm{Pb}$ в 1,1 раз, одной из причин которого может быть деятельность расположенной рядом АЗС [25, 26] либо автостанции (620 и 300 м соответственно).

Для территорий восточного региона были установлены следующие элементные ряды накопления по возрастанию концентраций ТМ в поверхностном слое почв селитебных территорий населенных пунктов Кировского района (с. Приветное, с. Яркое поле) и г. Керчь: $\mathrm{As}<\mathrm{Co}<\mathrm{Pb}<\mathrm{Cr}<\mathrm{Zn}<\mathrm{V}<\mathrm{Sr}<\mathrm{Cu}<\mathrm{Ni}$ и $\mathrm{As}<\mathrm{Co}<\mathrm{Pb}<\mathrm{Ni}<\mathrm{Cu}<\mathrm{Cr}<\mathrm{V}<\mathrm{Zn}<\mathrm{Sr}$. Для Кировского района было характерно превышение кларка почв населенных пунктов для $\mathrm{V}, \mathrm{Cr}, \mathrm{Co}, \mathrm{Ni}, \mathrm{Cu}$. При этом на одной из трех заложенных площадок в с. Яркое поле, расположенной в парковой зоне в 100 м от торгового центра, концентрации этих элементов были более высокими, отмечены превышения ПДК As в 6,6 раз и $\mathrm{Pb}$ в 1,2 раз. В почвах площадок мониторинга г. Керчь отмечено превышение кларка $\mathrm{Cu}$ в почвах населенных пунктов. На площадке № 27, расположенной на расстоянии 1,1 км от ТЭС, были отмечены превышения кларка почв населенных пунктов для V, Co, Ni. Ha Kepченском полуострове встречаются солонцеватые почвы и черноземы на тяжелых глинах, с чем может быть связано более высокое содержание Со и $\mathrm{Ni}[22,27]$.

В южном регионе был установлен следующий элементный ряд накопления по возрастанию концентраций ТМ в поверхностном слое урбопочв г. Алушта, г. Ялта, пгт. Кореиз: $\mathrm{Co}<\mathrm{Pb}<\mathrm{Cu}$, $\mathrm{Ni}<\mathrm{Cr}<\mathrm{V}<\mathrm{Zn}<\mathrm{Sr}$. В почвах г. Алушта были обнаружены превышения кларка почв населенных пунктов для $\mathrm{Cu}, \mathrm{Cr}, \mathrm{Ni}$, г. Ялта (площадка в парковой зоне) - V, Cr, Co, $\mathrm{Ni}, \mathrm{Cu}$, а также превышение ПДК $\mathrm{Pb}$ в 1,1 раза на площадке № 24. В пгт. Кореиз отмечены превышения кларка для $\mathrm{V}, \mathrm{Cr}, \mathrm{Co}, \mathrm{Ni}$, $\mathrm{Cu}$ в почвах населенных пунктов, а также превышение ПДК $\mathrm{Pb}$ в 1,1 раз. Что касается превышений $\mathrm{Pb}$, на территории Крымского природного заповедника в отдельные годы обнаруживались превышения критических нагрузок выпадений этого элемента с атмосферными осадками на $30 \%$ $[1,24]$.

Анализ рассчитанных коэффициентов техногенной концентрации элементов и суммарных по- казателей загрязнения (табл. 3) показал, что уровень загрязнения почв исследуемых площадок мониторинга селитебных зон Республики Крым является низким во всех регионах, однако выявлена некоторая дифференциация территорий по количеству элементов, для которых $K_{c}$ превышал 1 . Так, в Красноперекопском районе северного региона (с. Магазинка, с. Новопавловка) $K_{c}>1$ был для $\mathrm{V}, \mathrm{Cr}, \mathrm{Co}, \mathrm{Ni}, \mathrm{Cu}, \mathrm{Zn}$, в то время как на территории городского округа Армянск - только для $\mathrm{Cu}$. В восточном регионе $K_{c}>1$ отмечен для $\mathrm{V}, \mathrm{Co}, \mathrm{Ni}, \mathrm{Cu}$ на всех площадках за исключением площадки № 21, где $K_{c}$ элементов находились в пределах $0,5-1,0$, а также была отмечена более высокая концентрация $\mathrm{Cr}$ в Кировском районе, где $K_{c}$ составляли $1,1-1,3$. На площадках западного региона $\mathrm{K}_{\mathrm{c}}$ превышал либо был близок к 1 для $\mathrm{V}, \mathrm{Cr}, \mathrm{Co}, \mathrm{Ni}, \mathrm{Cu}$, в то время как для Zn $K_{c}$ составил 1,1-2,4 в с. Новофедоровка, с. Ромашкино и г. Саки. В северо-западном регионе превышения кларка населённых пунктов отмечены для $\mathrm{V}, \mathrm{Cr}, \mathrm{Co}, \mathrm{Ni}, \mathrm{Cu}$ на площадках № 5, 8, расположенных недалеко от шоссе, в пгт. Раздольное, где также $K_{c} \mathrm{~Pb}$ составил 1,5 . В Белогорском районе центрального региона $K_{c}>1$ для $\mathrm{Ni}, \mathrm{Cu}, \mathrm{Zn}$ в пгт. Зуя и $\mathrm{Sr}$ в г. Белогорск. В южном регионе на двух площадках № 10 и $24 K_{c}$ элементов были относительно низкими и не превышали кларки почв населённых пунктов, за исключением $K_{c} \mathrm{Co}$, который был равен 1,2 ; на остальных трёх площадках отмечены $K_{c}>1$ для $\mathrm{V}, \mathrm{Cr}, \mathrm{Co}, \mathrm{Ni}, \mathrm{Cu}$, а также $\mathrm{Zn}$ на площадке № 22, расположенной в парковой зоне на расстоянии 450 м от шоссе.

\section{Заключение}

Обобщая вышеизложенные результаты исследования содержания ТМ в почвах населенных пунктов северного, северо-западного, западного, центрального, восточного и южного регионов Республики Крым, можно отметить некоторые особенности их распределения в поверхностном слое почв указанных площадок мониторинга. Анализ территориального распределения элементов в почвах селитебных зон полуострова свидетельствует 0 том, что среди исследованных ТМ чаще всего превышения ПДК, ОДК и (или) кларков имели место для $\mathrm{Cr}, \mathrm{Co}, \mathrm{Pb}$ на площадках мониторинга Кировского, Красноперекопского и Сакского районов, которые принадлежат к разным географическим

Таблица 3. Коэффициенты техногенной концентрации $\left(K_{c}\right)$ и суммарные показатели загрязнения $\left(Z_{c}\right)$ тяжелых металлов в почвах площадок мониторинга селитебных зон Республики Крым, у.е.

Table 3. Coefficients of technogenic concentration $\left(K_{c}\right)$ and total rates of contamination $\left(Z_{c}\right)$ of heavy metals in soils of monitoring plots in residential zones of Crimea Republic, c.u.

\begin{tabular}{|l|c|c|c|c|c|c|c|c|c|c|}
\hline \multicolumn{1}{|c|}{ Регион/Region } & $K_{c} \mathrm{~V}$ & $K_{c} \mathrm{Cr}$ & $K_{c} \mathrm{Co}$ & $K_{c} \mathrm{Ni}$ & $K_{c} \mathrm{Cu}$ & $K_{c} \mathrm{Zn}$ & $K_{c} \mathrm{As}$ & $K_{c} \mathrm{Sr}$ & $K_{c} \mathrm{~Pb}$ & $Z_{c}$ \\
\hline Северный/Northern & $0,18-1,63$ & $0,53-1,74$ & $0,00-2,84$ & $0,00-2,61$ & $1,90-2,54$ & $0,50-1,01$ & 0,00 & $0,37-0,81$ & $0,00-0,93$ & $1,95-6,77$ \\
\hline $\begin{array}{l}\text { Северо-западный } \\
\text { Northwestern }\end{array}$ & $0,22-1,18$ & $0,57-1,12$ & $0,00-1,84$ & $0,00-1,70$ & $0,74-1,95$ & $0,44-1,49$ & $0,00-0,10$ & $0,31-0,92$ & $0,00-1,25$ & $0,00-3,64$ \\
\hline Западный/Western & $0,71-1,18$ & $0,75-1,21$ & $0,99-1,77$ & $0,82-1,85$ & $1,31-1,69$ & $0,56-2,36$ & $0,00-0,69$ & $0,40-0,95$ & $0,05-0,64$ & $1,54-4,12$ \\
\hline Центральный/Central & $0,38-0,86$ & $0,54-0,99$ & $0,42-0,99$ & $0,45-1,45$ & $1,05-1,74$ & $0,54-1,12$ & $0,00-0,07$ & $0,38-1,69$ & $0,15-0,60$ & $1,62-2,43$ \\
\hline Восточный/Eastern & $0,79-1,23$ & $0,76-1,27$ & $0,92-1,98$ & $0,82-1,91$ & $1,02-1,41$ & $0,60-0,93$ & $0,00-0,75$ & $0,29-0,54$ & $0,42-0,68$ & $2,28-3,55$ \\
\hline Южный/Southern & $0,10-1,34$ & $0,96-1,24$ & $0,28-1,36$ & $0,82-1,70$ & $0,90-1,38$ & $0,47-1,25$ & 0,00 & $0,26-0,54$ & $0,38-0,66$ & $0,00-3,19$ \\
\hline
\end{tabular}


регионам полуострова. При этом в Красноперекопском районе располагаются крупные промышленные предприятия Крыма; Сакский район и г. Саки - курортно-рекреационная территория, однако здесь находился и долгое время функционировал химический завод.

С другой стороны, учитывая то обстоятельство, что анализировали пробы почв селитебных территорий, можно полагать, что природный геохимический фон оказывает меньшее влияние на распределение и накопление ТМ по сравнению с антропогенным воздействием.

В пользу этого свидетельствует и сравнительный анализ содержания металлов с их кларками. Так, на всех участках валовое содержание $\mathrm{Cu}$ было выше установленного кларка этого элемента в почвах населенных пунктов. В почвах сел Красноперекопского района северной части полуострова выявлены превышения кларка почв населенных пунктов и ориентировочно допустимых концентраций для $\mathrm{V}, \mathrm{Cr}, \mathrm{Co}, \mathrm{Ni}, \mathrm{Zn}, \mathrm{Pb}$. Для территорий других регионов были характерны превышающие кларки почв населенных пунктов концентрации $\mathrm{Cr}, \mathrm{Co}$, Ni. Также на некоторых участках были выявлены содержания As, превышающие ПДК в несколько раз, и незначительные превышения $\mathrm{Pb}$. В почвах Сакского и Раздольненского районов встречались превышения ОДК Zn. В то же время в почвах исследуемых участков центрального, восточного и южного регионов пре-

\section{СПИСОК ЛИТЕРАТУРЫ}

1. Евстафьева Е.В. Оценка экологического риска для здоровья на территории Республики Крым // Проблемы анализа риска. 2014. - T. 11. - № 5. - С. 30-38.

2. Пространственно-временной анализ встречаемости онкологических заболеваний как индикатора медико-экологической безопасности / О.Е. Архипова, Е.А. Черногубова, Н.В. Лих танская, В.В. Кулыгин, И.В. Шевердяев, С.А. Куролап, С.А. Епринцев, В.А. Тарасов, Д.Г. Матишов. - Ростов н/Д: Изд-во Южного научного центра РАН, 2014. - 224 с.

3. Биогеохимические основы экологического нормирования / В.Н. Башкин, Е.В. Евстафьева, В.В. Снакин, И.О. Алябина, А.В. Антипова, П.П. Кречетов, Т.А. Кузовникова, В.Е. Мельченко, А.В. Степичев. - М.: Наука, 1993. - 304 с.

4. Armah F.A., Quansah R., Luginaah I. A Systematic Review of Heavy Metals of Anthropogenic Origin in Environmental Media and Biota in the Context of Gold Mining in Ghana // International Scholarly Research Notices. - 2014. - V. 2014. - P. 1-37.

5. Issaka S., Ashraf M.A. Impact of soil erosion and degradation on water quality: a review // Geology, Ecology and Landscapes. 2017. - V. 1. - № 1. - P. 1-11.

6. Hange K., Awofolu 0.R. Assessment of anthropogenic influence on the level of selected heavy metals $(\mathrm{Cu}, \mathrm{Zn}, \mathrm{Cd}$ and $\mathrm{Pb})$ in soil // Journal of Soil Science and Environmental Management. 2017. - V. 8. - № 6. - P. 113-121.

7. A review of toxicity and mechanisms of individual and mixtures of heavy metals in the environment / X. Wu, S.J. Cobbina, G. Mao, H. Xu, Z. Zhang, L. Yang // Environmental Science and Pollution Research. - 2016. - V. 23. - № 9. - P. 8244-8259.

8. Fractional and Group Composition of the $\mathrm{Mn}, \mathrm{Cr}$, Ni, and Cd compounds in the soils of technogenic landscapes in the impact zone вышения допустимых концентраций ТМ встречались в меньшей степени.

Все это в совокупности с вышеизложенным дает основание полагать, что наблюдаемые содержания большинства ТМ в значительной степени имеют антропогенное происхождение. Основными источниками поступления ТМ в почвах таких районов могут являться: сжигание топлива, аэрозольные выбросы предприятий химической, металлургической промышленности, автотранспорт, свалки бытовых, коммунальных и промышленных отходов, сточные воды, выбросы теплоэлектростанций, использование пестицидов и удобрений. Это требует дифференцированного анализа и идентификации источников поступления ТМ.

Полученные результаты подтверждают необходимость дальнейших исследований, в том числе мониторинга содержания TМ в почвах заповедных территорий и других звеньях биогеохимической трофической цепи, включая биосубстраты человека.

Исследование выполнено при поддержке Програмлы развития федерального государственного автономного образовательного учреждения высшего образования «Крылский федеральный университет имени В.И. Вернадского" на 2015-2024 годы по проекту «Сеть академической мобильности «Академическая мобильность молодых ученых России» в 2016 году» на базе кафедры почвоведения и оценки земельных ресурсов Южного Федерального Университета, а также проектной части госзадания № 5.948.2017/ПЧ, гранта Президента по поддержке ведущих научных школ, № HШI-3464.2018.11.

of the Novocherkassk Power Station / T.M. Minkina, G.V. Motuzova, S.S. Mandzhieva, 0.G. Nazarenko, M.V. Burachevskaya, E.M. Antonenko // Eurasian Soil Science. - 2013. - V. 46. № 4. - P. 375-385.

9. Forms of $\mathrm{Cu}$ (II), $\mathrm{Zn}$ (II), and $\mathrm{Pb}$ (II) compounds in technogenically transformed soils adjacent to the Karabashmed copper smelter / T.M. Minkina, V.G. Linnik, D.G. Nevidomskaya, T.V. Bauer, S.S. Mandzhieva, V. Khoroshavin // Journal of Soils and Sediments. - 2017. D0I: 10.1007/s11368-017-1708-2.

10. Baktybaeva Z.B., Yamalov S.M., Suyundukov Y.T. Effect of Heavy Metal Pollution on Plant Communities of the Tanalyk River, the Bashkir Transural Region // Russian Journal of Ecology. 2011. - V. 42. - № 5. - P. 378-381.

11. Аккумуляция тяжелых металлов в почвах и травянистой растительности в окрестностях золотоизвлекательной фабрики (Республика Башкортостан) / И.Н. Семенова, Я.Т. Суюндуков, Р.Ф. Хасанова, Ю.С. Рафикова, Г.Я. Биктимерова, Л.Н. Белан, А.Б. Зулкарнаев // Проблемы региональной экологии. 2017. - № 2. - C. 5-9.

12. Heavy metal content in urban soils as an indicator of anthropogenic and natural influences on landscape of Karachi - a multivariate spatio-temporal analysis / Z. Karim, B.A. Qureshi, M. Mumtaz, S. Qureshi // Ecological indicators. - 2014. - V. 42. P. 20-31.

13. Gu Y.G., Gao Y.P., Lin Q. Contamination, bioaccessibility and human health risk of heavy metals in exposed-lawn soils from 28 urban parks in southern China's largest city, Guangzhou // Applied Geochemistry. - 2016. - V. 67. - P. 52-58.

14. ГОСТ 17.4.4.02-84. Охрана природы. Почвы. Методы отбора и подготовки проб для химического, бактериологического и гельминтологического анализа. Госстандарт. - М.: Изд. ФГУП «Стандартинформ», 2008. - 8 c. 
15. МУ 2.1.7.730-99. Гигиеническая оценка качества почвы населённых мест. - М.: Федеральный центр госсанэпид надзора Минздрава России, 1999. - 7 с.

16. ГОСТ 29269-91. Почвы. Общие требования к проведению анализов. - М.: Комитет стандартизации и метрологии СССР, 1991. -10 c.

17. ГН 2.1.7.2041-06. Предельно-допустимые концентрации (ПДК) химических веществ в почве: Гигиенические нормативы. - М.: Федеральный центр гигиены и эпидемиологии Роспотребнадзора, 2006. - 15 с.

18. ГН 2.1.7.2511-09. Ориентировочно-допустимые концентрации (ОДК) химических веществ в почве: Гигиенические нормативы. - М.: Федеральный центр гигиены и эпидемиологии Роспотребнадзора, 2009. - 11 с.

19. Алексеенко В.А., Алексеенко А.В. Химические элементы в геохимических системах. Кларки почв селитебных ландшафтов: монография. - Ростов н/Д: Изд-во Южного федерального университета, 2013. - 380 с.

20. Геохимия окружающей среды / Ю.Е. Сает, Б.А. Ревич, Е.П. Янин, Р.С. Смирнова, И.Л. Башаркевич, Т.Л. Онищенко, Л.Н. Павлова, Н.Я. Трефилова, А.И. Ачкасов, С.Ш. Саркисян. - М.: Недра, 1990. - 335 с.

21. Ярош О.Б., Кобечинская В.Г. Оптимизация девастированных территорий Республики Крым: возможности и риски // Актуальные вопросы современной науки. - 2015. - Т. 43. C. 114-123.

22. Драган Н.А. Почвенные ресурсы Крыма. Научная монография. 2-е изд., доп. - Симферополь: Доля, 2004. - 208 с.
23. Aslam J., Khan S.A., Khan S.H. Heavy metals contamination in road side soil near different traffic signals in Dubai, United Arab Emirates // J Saudi Chemical Society. - 2013. - V. 17. - № 3. P. 315-319.

24. Оценка негативного воздействия свинца на заповедные территории Крыма с использованием европейских и отечественных подходов / Е.В. Евстафьева, А.М. Богданова, А.В. Паршинцев, С.Л. Тымченко, Г.П. Нараев, Н.А. Сологуб // Тезисы VIII Международной научно-практической конференции «Заповедники Крыма - 2016: биологическое и ландшафтное разнообразие, охрана и управление». - Симферополь, 2016. C. $127-129$.

25. Накопление тяжелых металлов в почвах агломерации Волгоград - Волжский в условиях антропогенеза / В.Н. Заикина, Е.А. Фирсенко, Ю.А. Свиридова, А.А. Околелова // Сборник докладов I Международного заочного конкурса научно-исследовательских работ // научный ред. А.В. Гумеров. - Казань: 000 «Ро́кета Союз», 2015. - Т. 3. - С. 136-141.

26. Князев А.В., Мустафина Ю.Ф., Сивкова Г.А. Определение содержания тяжелых металлов в почве на территориях АЗС // Новая наука: Опыт, традиции, инновации, 2015. - № 7-2. C. 202-204.

27. Alloway B.J. Sources of heavy metals and metalloids in soils // Heavy metals in soils. Environmental Pollution. - 2013. V. 22. - P. 11-50.

Поступила 16.03.2018 г.

\section{Информация об авторах}

Eвстафьева E.B., доктор медицинских наук, доктор биологических наук, профессор, заведующая кафедрой физиологии нормальной Медицинской академии им. С.И. Георгиевского и отдела экологических рисков Медицинской академии им. С.И. Георгиевского Крымского Федерального Университета им. В.И. Вернадского).

Богданова A.M., младший научный сотрудник Центральной научно-исследовательской лаборатории; аспирант кафедры физиологии нормальной Медицинской академии им. С.И. Георгиевского Крымского Федерального Университета им. В.И. Вернадского.

Минкина T.M., доктор биологических наук, профессор, заведующая кафедрой почвоведения и оценки земельных ресурсов Академии биологии и биотехнологии Южного Федерального Университета.

Сушкова С.H., кандидат биологических наук, старший научный сотрудник научно-исследовательской лаборатории мониторинга биосферы Академии биологии и биотехнологии Южного Федерального Университета.

Барановская Н.B., доктор биологических наук, профессор кафедры геоэкологии и геохимии отделения геологии Инженерной школы природных ресурсов Национального исследовательского Томского политехнического университета.

Манджиева С.С., кандидат биологических наук, ведущий научный сотрудник научно-исследовательской лаборатории мониторинга биосферы Академии биологии и биотехнологии Южного Федерального Университета.

Антоненко E.M., кандидат технических наук, старший научный сотрудник кафедры почвоведения и оценки земельных ресурсов Академии биологии и биотехнологии Южного Федерального Университета. 
UDC: $546.3: 614.76: 574.24(-2)(470+571)$

\title{
HEAVY METALS CONTENT IN SOILS OF RESIDENTIAL TERRITORIES OF CRIMEA REPUBLIC
}

\author{
Elena V. Evstafeva',
}

e.evstafeva@mail.ru

\section{Anna M. Bogdanova',}

annuta2607@yandex.ru

Tatiana M. Minkina ${ }^{2}$,

tminkina@mail.ru

\section{Svetlana N. Sushkova ${ }^{2}$,}

svetlana.sushkova.sfedu@gmail.com

\section{Natalia V. Baranovskaya ${ }^{3}$, nata@tpu.ru}

\section{Saglara S. Mandzhieva²,}

msaglara@mail.ru

\author{
Elena M. Antonenko², \\ emantonenko@sfedu.ru \\ ${ }^{1}$ V.I. Vernadsky Crimean Federal University, \\ 5/7, Lenin Avenue, Simferopol, 295006, Russia. \\ 2 Southern Federal University, \\ 194/1, Stachki avenue, Rostov-on-Don, 344090, Russia. \\ ${ }^{3}$ National Research Tomsk Polytechnic University, \\ 30, Lenin Avenue, Tomsk, 634050, Russia.
}

The relevance of the research is caused by the need to monitor heavy metal content in ecosystems and human bio-substrates as the initial stage in assessing their impact on ecosystems and human body for determination the regional ecological standards taking into account natural and technogenic specificity of the region.

The aim of this study was to evaluate soil content of $\mathrm{Pb}, \mathrm{Zn}, \mathrm{Sr}, \mathrm{Cu}, \mathrm{Ni}, \mathrm{Co}, \mathrm{Cr}, \mathrm{As}, \mathrm{V}$ at 30 monitoring sites of residential areas in the central, southern, eastern, northwestern, western and northern regions of the Crimean peninsula.

Methods. The total content of $\mathrm{Pb}, \mathrm{Zn}, \mathrm{Sr}, \mathrm{Cu}, \mathrm{Ni}, \mathrm{Co}, \mathrm{Cr}, \mathrm{As}, \mathrm{V}$ in samples of soil was determined using $\mathrm{x}$-ray spectrometer "Spektroskan Max-GV" in the laboratory of Soil Science Department in Academy of biology and biotechnology in Southern Federal University.

Results. Exceedances of the maximum permissible concentrations were determined for $\mathrm{Cr}, \mathrm{Co}, \mathrm{Pb}$, while As and $\mathrm{Zn}$ showed excess rarely. The maximum values of exceedances were as follows: 6,6 for $A s ; 2,1$ for $P b ; 1,1$ for $V ; 1,7$ for $Z n ; 1,1$ for Ni of maximum permissible concentration, 2,8 for Co; 2,6 for Cu; 1,7 for Cr and Sr of clarkes for settlements. The comparative analysis of heavy metals distribution in soil of the regions with different natural and anthropogenic conditions allows assuming that the revealed heavy metals exceedances are mostly of an anthropogenic origin. Further studies including the reserved territories of the Crimea are needed to identify the geochemical soil characteristics and their origin at different regions.

Key words:

Soil, heavy metals, ecological monitoring, residential territories, Crimean peninsula.

The research was supported by the Program of development of Crimea Federal University named after V.I. Vernadsky for 2015-2024 by the project "Network of academic mobility "Academic mobility of young scientists in Russia" in 2016» at the department of soil science and estimation of land resources at Southern Federal University and the project part of the State Task no. 5.948.2017/PCh, grant of the President of the RF for supporting leading scientific schools, no. NSh-3464.2018.11.

\section{REFERENCES}

1. Evstafeva E.V. Assessing the environmental risk to health in the Republic of Crimea. Problemy analiza riska, 2014, vol. 11, no. 5 , pp. 30-38. In Rus.

2. Arhipova O.E., Chernogubova E.A., Likhtanskaya N.V., Kulygin V.V., Sheverdyaev I.V., Kurolap S.A., Eprintsev S.A., Tarasov V.A., Matishov D.G. Prostranstvenno-vremennoy analiz vstrechaemosti onkologicheskikh zabolevaniy kak indikatora me- diko-ekologicheskoy bezopasnosti [Spatio-temporal analysis of occurrence of oncologic diseases as an indicator of medical and ecological safety]. Rostov n/D, Southern Scientific Center RAN Publ., 2014. 224 p.

3. Bashkin V.N., Evstafyeva E.V., Snakin V.V., Alyabina I.0., Antipova A.V., Krechetov P.P., Kuzovnikova T.A., Melchenko V.E., Stepichev A.V. Biogeokhimicheskiye osnovy ekologicheskogo normirovaniya [Biochemical bases of environmental regulation]. Moscow, Nauka Publ., 1993. 312 p. 
4. Armah F.A., Quansah R., Luginaah I. A Systematic Review of Heavy Metals of Anthropogenic Origin in Environmental Media and Biota in the Context of Gold Mining in Ghana. International Scholarly Research Notices, 2014, vol. 2014, pp. 1-37.

5. Issaka S., Ashraf M.A. Impact of soil erosion and degradation on water quality: a review. Geology, Ecology and Landscapes, 2017, vol. 1, no. 1, pp. 1-11.

6. Hange K., Awofolu 0.R. Assessment of anthropogenic influence on the level of selected heavy metals $(\mathrm{Cu}, \mathrm{Zn}, \mathrm{Cd}$ and $\mathrm{Pb})$ in soil. Journal of Soil Science and Environmental Management, 2017, vol. 8, no. 6, pp. 113-121.

7. Wu X., Cobbina S.J., Mao G., Xu H., Zhang Z., Yang L. A review of toxicity and mechanisms of individual and mixtures of heavy metals in the environment. Environmental Science and Pollution Research, 2016, vol. 23, no. 9, pp. 8244-8259.

8. Minkina T.M., Motuzova G.V., Mandzhieva S.S., Nazarenko 0.G., Burachevskaya M.V., Antonenko E.M. Fractional and Group Composition of the $\mathrm{Mn}, \mathrm{Cr}, \mathrm{Ni}$, and $\mathrm{Cd}$ compounds in the soils of technogenic landscapes in the impact zone of the Novocherkassk Power Station. Eurasian Soil Science, 2013, vol. 46, no. 4, pp. 375-385.

9. Minkina T.M., Linnik V.G., Nevidomskaya D.G., Bauer T.V., Mandzhieva S.S., Khoroshavin V. Forms of $\mathrm{Cu}$ (II), Zn (II), and Pb (II) compounds in technogenically transformed soils adjacent to the Karabashmed copper smelter. Journal of Soils and Sediments, 2017. DOI: 10.1007/s11368-017-1708-2

10. Baktybaeva Z.B., Yamalov S.M., Suyundukov Y.T. Effect of Heavy Metal Pollution on Plant Communities of the Tanalyk River, the Bashkir Transural Region. Russian Journal of Ecology, 2011, vol. 42 , no. 5, pp. 378-381.

11. Semenova I.N., Suyundukov Ya.T., Khasanova R.F., Rafikova Yu.S., Biktimerova G.Ya., Belan L.N., Zulkarnayev A.B. Accumulation of heavy metals in soils and grassy vegetation in the neighborhood of gold-extracting factory (Republic of Bashkortostan). Problemy regionalnoy ekologii, 2017, no. 2, pp. 5-9. In Rus.

12. Karim Z., Qureshi B. A., Mumtaz M., Qureshi S. Heavy metal content in urban soils as an indicator of anthropogenic and natural influences on landscape of Karachi - a multivariate spatio-temporal analysis. Ecological indicators, 2014, vol. 42, pp. 20-31.

13. Gu Y.G., Gao Y.P., Lin Q. Contamination, bioaccessibility and human health risk of heavy metals in exposed-lawn soils from 28 urban parks in southern China's largest city, Guangzhou. Applied Geochemistry, 2016, vol. 67, pp. 52-58.

14. GOST 17.4.4.02-84. Okhrana prirody. Pochvy. Metody otbora i podgotovki prob dlya khimicheskogo, bakteriologicheskogo i gelmintologiche skogo analiza [SS 17.4.4.02-84. Conservation. Soils. Methods of selection and preparation of tests for chemical, bacteriological and helminthological analysis]. Moscow, Standartinform Publ., 2008. 8 p.

15. MU 2.1.7.730-99. Gigienicheskaya otsenka kachestva pochvy naselennykh mest [Hygienic assessment of quality of the soil in inhabited places]. Moscow, Federal Center of State sanitary-epidemiological control Ministry of Health of the RF, 1999. 7 p.

16. GOST 29269-91. Pochvy. Obshhie trebovaniya k provedeniyu analizov [SS 29269-91. Soils. General requirements to carrying out analyses]. Moscow, Komitet standartizatsii i metrologii SSSR, 1991.10 p.
17. GN 2.1.7.2041-06. Predelno-dopustimye kontsentratsii (PDK) khimicheskikh veshchestv v pochve: gigienicheskie normativy [The Maximum-permissible Concentration (MPC) of chemicals in the soil: Hygienic standards]. Moscow, Federal center of hygiene and epidemiology of Rospotrebnadzor, 2006. $15 \mathrm{p}$.

18. GN 2.1.7.2511-09. Orientirovochno-dopustimye kontsentratsii (ODK) khimicheskikh veshchestv v pochve: gigienicheskie normativy [Approximate and Admissible Concentration (AAC) of chemicals in the soil: Hygienic standards]. Moscow, Federal center of hygiene and epidemiology of Rospotrebnadzor, 2009.11 p.

19. Alekseenko V.A., Alekseenko A.V. Khimicheskie ehlementy v geokhimicheskikh sistemakh. Klarki pochv selitebnykh landshaftov: monografiya [Chemical elements in geochemical systems. Clarcs of soils of residential landscapes: monograph]. Rostov n/D, Southern Federal University Press, 2013. 380 p.

20. Saet Yu.E., Revich B.A., Yanin E.P., Smirnova R.S., Basharkevich I.L., Onishchenko T.L., Pavlova L.N., Trefilova N.Ya., Achkasov A.I., Sarkisyan S.Sh. Geokhimiya okruzhayushchey sredy [Environment geochemistry]. Moscow, Nedra Publ., 1990. 335 p.

21. Yarosh 0.B., Kobechinskaya V.G. Optimization of soils in the Republic of Crimea: opportunities and risks. Aktualnye voprosy sovremennoy nauki, 2015, vol. 43, pp. 114-123. In Rus.

22. Dragan N.A. Pochvennye resursy Kryma [Soil resources of the Crimea. Monograph]. Simferopol, Dolya Publ., 2004. 208 p.

23. Aslam J., Khan S.A., Khan S.H. Heavy metals contamination in road side soil near different traffic signals in Dubai, United Arab Emirates. Journal Saudi Chemical Society, 2013, vol. 17, no. 3, pp. 315-319.

24. Evstafeva E.V., Bogdanova A.M., Parshintsev A.V., Tymchenko S.L., Naraev G.P., Sologub N.A. Otsenka negativnogo vozdeystviya svintsa na zapovednye territorii Kryma s ispolzovaniem evropeyskikh i otechestvennykh podkhodov [Assessment of negative impact of lead on reserved territories of the Crimea using the European and domestic approaches]. Tezisy VIII Mezhdunarodnoy nauchno-prakticheskoy konferentsii. Zapovedniki Kryma 2016: biologicheskoe i landshaftnoe raznoobrazie, okhrana i upravlenie [Proc. of the VIII International scientific and practical conference. Crimea Reserves - 2016: biological and landscape diversity, protection and management]. Simferopol, 2016. pp. 127-129.

25. Zaikina V.N., Firsenko E.A., Sviridova Yu.A., Okolelova A.A. Nakoplenie tyazhelykh metallov v pochvakh aglomeratsii Volgograd Volzhsky v usloviyakh antropogeneza [Accumulation of heavy metals in soils of agglomeration Volgograd - Volzhsky in the conditions of anthropogenesis]. Sbornik dokladov I Mezhdunarodnogo $z a$ ochnogo konkursa nauchno-issledovatelskikh rabot [Collection of reports of the I International correspondence competition of research works]. Kazan, Róketa Soyuz Publ., 2015. Vol. 3, pp. 136-141.

26. Knyazev A.V., Mustafina Yu.F., Sivkova G.A. Opredelenie soderzhaniya tyazhelykh metallov v pochve na territoriyakh AZS [Determination of content of heavy metals in the soil in gas station territories]. $\mathrm{No}$ vaya nauka: Opyt, traditsii, innovatsii, 2015, no. 7-2, pp. 202-204.

27. Alloway B.J. Sources of heavy metals and metalloids in soils. Heavy metals in soils. Environmental Pollution, 2013, vol. 22, pp. 11-50.

Received: 16 March 2018.

\section{Information about the authors}

Elena $\boldsymbol{V}$. Evstafeva, Dr. Sc., professor, head of the department, V.I. Vernadsky Crimean Federal University.

Anna M. Bogdanova, postgraduate student, V.I. Vernadsky Crimean Federal University.

Tatiana M. Minkina, Dr. Sc., professor, head of the department, Southern Federal University.

Svetlana N. Sushkova, Dr. Sc., senior researcher, Southern Federal University.

Natalia V. Baranovskaya, Dr. Sc., professor, National Research Tomsk Polytechnic University.

Saglara S. Mandzhieva, Dr. Sc., leading researcher, Southern Federal University.

Elena M. Antonenko, Dr. Sc., senior researcher, Southern Federal University. 